\title{
Editorial
}

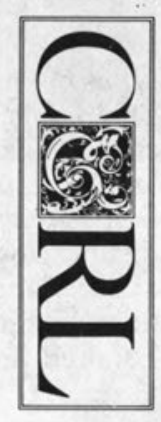

\section{Autonomy and Bureaucracy}

When I was a boy in Boston, the works of Nathaniel Hawthorne, Ralph Waldo Emerson, and Henry Wadsworth Longfellow were schoolroom standards. I recall that the most educated men in the colonies were alleged to have relied heavily for their earthly inspiration on just three works: the Bible, Pilgrim's Progress, and Paradise Lost. I envied these men. I envied their ability to reach a state of earthly contentment based on exposure to so few works. As a boy I even felt guilty that my need to find universal meaning required exposure to a wider range of literatures and experiences.

Today, my introspective abilities are more sophisticated. I realize now that, unlike some early colonists, I have difficulty accepting without question the givens provided by others. In my view, established standards need to be challenged regularly in order to verify their continuing viability or truthfulness.

Upon entering librarianship, I was told that our professionalism is, as a given, naturally circumscribed by its bureaucratic setting. While I acknowledged this setting, I added "but it is not by definition naturally circumscribed."

Generally, the bureaucracy facilitates our traditional attitudes and behaviors rather effectively. It has even shown a remarkable degree of flexibility in accommodating rapid changes in automated technologies. My interpretation is that the limits on our professionalism are largely self-imposed. The bureaucracy is our agent. If it circumscribes, then that is our will.

One of the severest tests that bureaucracies face occurs when members want to increase their autonomy. In librarianship the existing level of autonomy is sufficient to allow us to carry out our traditional roles satisfactorily. Therefore, we do not need any significant lessening of bureaucracy. There is notwithstanding a role beyond the traditional one.

In his working paper, "1985-1995: The Next Decade in Academic Librarianship," the first part of which appears in this issue of College $\mathcal{E}$ Research Libraries, Allen Veaner describes the outline of this role. According to Veaner, "the broad and general removal of production/manufacturing work from academic librarians is the most important change and the most valuable opportunity now before the ACRL community." Librarians are urged to move away from a "passive, reactive behavior" and to adopt an active and creative role. To fill this role we will have to move from the information business to the knowledge business. We will have to move our focal point of attention to the space between the printed word (or the visual image) and the human mind. This is the information transfer zone.

In the Client-Centered Academic Library, I define information transfer as "the degree to which the knowledge contained in a communication enables the receiver of that knowledge to move nearer to desired and/or beneficial outcomes for that user." If we begin to offer analysis, synthesis, and informed judgment about the content of materials, if we become involved in the degree to which our clients are successful in using the library, then, as librarians, our need for more autonomy will be obvious and compelling. At this time a further lessening of bureaucracy will be necessary.

In the July issue, the second part of Allen Veaner's article will appear. It deals with the 
types of knowledge, skills, abilities, and attitudes librarians will need in the next decade. The requisite shift in the responsibilities of academic librarians will mandate major role changes. The issues of autonomy and bureaucracy will become increasingly important, not less so, especially if we attempt to increase the relevancy and responsiveness of our libraries to external needs. In this sense, Allen Veaner's emphasis on the people factor, as distinct from collections, is crucial. In order to move into the information transfer area, we, as librarians, must decide to change the traditional role. This process has unusual implications for our current bureaucracies since knowledge work requires that we set aside timehonored professional constraints that provide narrow limits on what we will do for our users. It requires that we develop new roles and new expectations about how those roles are performed.

CHARLES MARTELL 